\title{
Shared gut feelings
}

Citation for published version (APA):

Jonkers, D. M. A. E. (2020). Shared gut feelings. Maastricht University. https://doi.org/10.26481/spe.20200124dj

Document status and date:

Published: 24/01/2020

DOI:

10.26481/spe.20200124dj

Document Version:

Publisher's PDF, also known as Version of record

\section{Please check the document version of this publication:}

- A submitted manuscript is the version of the article upon submission and before peer-review. There can be important differences between the submitted version and the official published version of record.

People interested in the research are advised to contact the author for the final version of the publication, or visit the DOI to the publisher's website.

- The final author version and the galley proof are versions of the publication after peer review.

- The final published version features the final layout of the paper including the volume, issue and page numbers.

Link to publication

\footnotetext{
General rights rights.

- You may freely distribute the URL identifying the publication in the public portal. please follow below link for the End User Agreement:

www.umlib.nl/taverne-license

Take down policy

If you believe that this document breaches copyright please contact us at:

repository@maastrichtuniversity.nl

providing details and we will investigate your claim.
}

Copyright and moral rights for the publications made accessible in the public portal are retained by the authors and/or other copyright owners and it is a condition of accessing publications that users recognise and abide by the legal requirements associated with these

- Users may download and print one copy of any publication from the public portal for the purpose of private study or research.

- You may not further distribute the material or use it for any profit-making activity or commercial gain

If the publication is distributed under the terms of Article $25 \mathrm{fa}$ of the Dutch Copyright Act, indicated by the "Taverne" license above, 
Mw. Prof. Dr. Daisy M.A.E. Jonkers

Faculty of Health, Medicine and Life Sciences

\section{Shared gut feelings}




\section{Tekst oratie 'shared gut feelings', Profileringsleerstoel Darmgezondheid}

Geachte Mevrouw de rector magnificus, zeer gewaardeerde collegae, beste familie en vrienden, het is voor mij een eer vandaag mijn inaugurele rede voor $u$ uit te spreken, getiteld 'shared gut feelings'.

Zoals dat geldt voor vele organen in het lichaam, is ook een goede darmfunctie belangrijk om ons goed te voelen en om goed te functioneren in het dagelijks leven. Maar een gezonde darm is ook belangrijk voor het functioneren van andere organen in het lichaam. Hippocrates, een belangrijke grondlegger van de hedendaagse Westerse geneeskunde, gaf 2400 jaar geleden al aan dat alle ziekten in de darmen beginnen. Dat is natuurlijk te kort door de bocht, maar toont wel het belang van een goede darmfunctie.

Graag wil ik de komende 45 minuten mijn profileringsleerstoel Darmgezondheid toelichten en daarbij het belang benadrukken van samenwerking, in de breedste zin van het woord.

In NL hebben ongeveer 2 miljoen mensen een Maag- Darm- of Leveraandoening, variërend van milde klachten tot ernstige ziekten, met veel impact op de kwaliteit van leven en samenhangend met hoge kosten. Dit betreft directe zorgkosten voor bijvoorbeeld medicatie, consulten en ziekenhuisopnames, maar ook indirecte kosten door bijv. verminderde arbeidsparticipatie. Voorbeelden van veel voorkomende darmaandoeningen zijn het prikkelbare darm syndroom, inflammatoire darmziekten en darmkanker. Verstoringen in darmgezondheid leiden echter niet alleen tot darmaandoeningen maar kunnen ook een rol spelen bij andere aandoeningen, zoals bijvoorbeeld alcoholische en vetleverziekten en metabole aandoeningen, zoals suikerziekte en obesitas. Deze zijn allen geassocieerd met een westerse levensstijl.

Een gezonde darm is moeilijk te definiëren omdat het diverse functies omvat die elkaar kunnen beïnvloeden en die vaak in meerdere of mindere mate een rol spelen bij diverse aandoeningen. 
Allereerst zal ik het belang van de darm barrière en de intestinale microbiota hierbij nader toelichten en ingaan op de rol van voeding hierbij.

Hier ziet $u$ een schematisch overzicht van ons spijsverteringsstelsel. Voedsel passeert de slokdarm en komt in de maag terecht. Na menging met maagsap, wordt het beetje bij beetje geledigd in de dunne darm. Hier vindt het merendeel van de afbraak van voedsel plaats met behulp van diverse spijsverteringssappen, en vervolgens worden de afzonderlijke nutriënten van het verteerde voedsel opgenomen. De dunne darm is zo'n 6 meter lang en heeft een oppervlakte zo groot als een tennisveld door de aanwezigheid van plooien, villi (ofwel darmvlokken) en microvilli.

Wat niet wordt afgebroken of opgenomen, komt vervolgens in de dikke darm ofwel het colon. De dikke darm is zo'n 1,5 m lang. Hier wordt het restmateriaal opgeslagen en omgezet door de aanwezige bacteriën. $\mathrm{Er}$ wordt nog water en elektrolyten opgenomen zodat de ontlasting vaster wordt voordat deze het lichaam verlaat.

Een normale stoelgang is voor iedereen anders en varieert tussen enkele keren per dag tot zo'n 3-4 keer per week. Problemen met de ontlasting, verstopping of juist diarree, kunnen tot vervelende klachten leiden, die grote invloed kunnen hebben op het functioneren in het dagelijks leven. Regelmatig vragen wij patiënten en vrijwilligers om ontlasting te verzamelen, om verder inzicht te krijgen in processen die plaatsvinden in de darm. Dit lijkt eenvoudig maar goede kwaliteit is hierbij essentieel, daar het belangrijk is dat de samples vers zijn en direct na verzameling worden ingevroren om processen stil te leggen. De komende tijd moeten we verder inzetten op verzamelen van goede kwaliteit samples in samenwerking met de patiënt, maar moeten we daarbij ook oog houden voor de belasting voor de patiënt.

Onze darmwand bestaat uit meerdere lagen bestaande uit spierweefsel, bindweefsel en het slijmvlies. Deze binnenste laag, het slijmvlies, staat in contact met de darminhoud en vormt een belangrijke barrière tegen invloeden van buiten, zoals schadelijke stoffen uit de voeding en de 
grote hoeveelheden bacteriën die aanwezig zijn in onze darm. Deze barrière wordt gevormd door het darmepitheel. Deze bekleding aan de binnenkant van de darm bestaat uit een laag aaneengesloten darmepitheelcellen. De cellen zijn bedekt met een beschermende slijmlaag. Daarnaast worden diverse antibacteriële eiwitten en antilichamen uitgescheiden, die bacteriën binden en doden en zo voorkomen dat ze ons lichaam binnen kunnen dringen. Onder de cellaag bevindt zich het in de darm aanwezige immuunsysteem. Al deze elementen samen zorgen ervoor dat ons inwendige milieu wordt beschermd tegen mechanische, chemische en microbiële invloeden van buitenaf.

Een belangrijke functie is hierbij weggelegd voor het darmepitheel. Dit bestaat uit slechts een enkele laag cellen, die met elkaar verbonden zijn middels eiwitcomplexen, bestaande uit tight junctions, adherens junctions en desmosomen. Dit eiwitcomplex is een heel dynamisch geheel en zorgt er voor dat water en ionen kunnen passeren, terwijl bacteriën en toxische stoffen worden tegengehouden.

Een verstoring van deze barrière functie kan er toe leiden dat bacteriën en schadelijke stoffen de cellaag kunnen passeren en in contact komen met ons afweersysteem en zenuwcellen. Dit kan bijvoorbeeld leiden tot ontsteking in de darm. Het kan echter ook bijdragen aan ontsteking elders in het lichaam, doordat bacteriën of hun producten in de circulatie terechtkomen.

Er zijn aanwijzingen dat de darm barrière functie verstoord is bij diverse ziekten en een rol kan spelen bij het ontstaan of de progressie van niet alleen darmaandoeningen maar ook andere aandoeningen. De barrière functie kan beïnvloed worden door genetische en epi-genetische factoren, maar ook door omgevingsfactoren die samenhangen met onze levensstijl. Hierbij kunt u bijv. denken aan medicijnen zoals pijnstillers (de NSAIDs, zoals ibuprofen), maar ook vetrijk eten en alcohol. Binnen ons onderzoek hebben we aangetoond dat 2 glazen alcohol er al voor zorgen dat de darm lek is. Gelukkig weten we ook dat dit slechts tijdelijk is, waardoor we na afloop van deze oratie toch met een gerust 
hart samen het glas kunnen heffen. Pas wel op , want dit is anders bij chronisch alcohol gebruik.

Daarnaast kunnen ook bepaalde bacteriën in onze darmen en hun producten, de darm barrière beschadigen of juist versterken. De samenstelling van onze darmflora ofwel microbiota, is hierbij van belang.

In 1676 heeft Antoni van Leeuwenhoek de basis gelegd voor onze kennis van bacteriën, toen hij onder zijn microscoop ' kleine diertjens' ontdekte. Inmiddels weten we dat er grote hoeveelheden bacteriën leven in en op ons lichaam, in harmonie met ons, en met diverse belangrijke functies voor ons als gastheer.

Relatief lage aantallen bacteriën zijn te vinden in de maag, onder invloed van onder andere het maagzuur. Vervolgens nemen de aantallen toe in de dunne darm, met de hoogste aantallen in de dikke darm, onder invloed van de passagetijd in de darm, de aanwezigheid van nutriënten, de $\mathrm{pH}$ en zuurstofspanning. Hier bevinden zich zo'n $10^{12}$ ofwel een biljoen bacteriën per gram darminhoud. Hiervan is het grootste gedeelte anaeroob en kan alleen leven in afwezigheid van zuurstof. In totaal hebben we zo'n 1.5-2 kg bacteriën in onze darm en hebben we ongeveer evenveel bacteriën als cellen in ons lichaam.

Deze microbiota is een heel complex ecosysteem, waarin meer dan 1000 soorten bacteriën aanwezig kunnen zijn, die samenwerken met elkaar en met ons. De samenstelling van de microbiota zoals $u$ hier allen zit, is voor iedereen uniek. We kunnen deze zien als een soort van vingerafdruk, maar dan van uw microbiota. Deze samenstelling is ook relatief stabiel gedurende uw leven.

Deze intestinale microbiota hebben we nodig. Deze heeft diverse belangrijke functies voor ons als gastheer. Hij draagt bij aan de bescherming tegen pathogene ofwel schadelijke bacteriën door de competitie aan te gaan voor plekken en voedingsstoffen. Daarnaast stimuleert onze microbiota de rijping en het goed functioneren van het darmepitheel en het onderliggende immuunsysteem, en is daarmee ook 
belangrijk voor een goede barrière functie van de darm. Bacteriën en hun producten kunnen onder andere de productie van slijm, antibacteriële eiwitten en het functioneren van de eiwitcomplexen tussen de epitheelcellen beïnvloeden. Daarnaast heeft de microbiota ook een zeer sterke metabole capaciteit. Door al deze functies heeft de intestinale microbiota hierdoor invloed op diverse darmfuncties maar ook op ander organen in het lichaam, zoals bijvoorbeeld onze hersenen, de lever en het vetweefsel.

De metabole activiteit van de microbiota werd al gezien door Elie Mechnikoff. Deze Russische microbioloog, kreeg 1908 samen met Paul Ehrlich de Nobelprijs voor zijn werk aan fagocytose binnen de immunologie. Hij ging er vanuit dat de complexe microbiota in de dikke darm, een slechte invloed had op de gastheer door de productie van toxische stoffen bij de anaerobe afbraak van eiwitten. Hij ontdekte dat het regelmatig gebruik van melkzuurbacteriën in gefermenteerde zuivelproducten een gunstig effect had en geassocieerd was met gezondheid en ouderdom.

Deze observatie van Mechnikoff hangt samen met de sterke metabole activiteit van onze microbiota. De microbiota wordt ook wel gezien als een extra orgaan, een grote fabriek waar veel stoffen geproduceerd en omgezet worden. Zo worden bijvoorbeeld vitamines geproduceerd, galzuren en medicijnen omgezet, en worden koolhydraten en eiwitten omgezet, ofwel gefermenteerd.

Koolhydraten die niet worden afgebroken en/of opgenomen in onze dunne darm, zoals vezels, worden door de bacteriën in de dikke darm omgezet in korteketenvetzuren en gas. Dit proces heeft saccharolytische fermentatie (de afbraak van koolhydraten door bacteriën in afwezigheid van zuurstof). De geproduceerde korteketenvetzuren hebben diverse gunstige effecten. Ze zijn een energiebron voor de darmepitheelcellen, ze remmen onder andere ontsteking en versterken de darm barrièrefunctie.

Als er geen koolhydraten zijn, gaat de microbiota over op eiwitten afkomstig uit de voeding en van bijvoorbeeld dode cellen. Hierbij 
worden veelal metabolieten geproduceerd die juist schadelijk zijn voor onze darmwand. Vanuit de microbiota bezien, hebben we een voorkeur voor koolhydraten waarbij gunstige metabolieten worden geproduceerd, ten opzichte van de fermentatie van eiwitten (ofwel proteolytische fermentatie), waarbij meer schadelijke metabolieten vrijkomen.

Inmiddels weten we ook dat belangrijke verschillen in voedingsinname de samenstelling en met name de activiteit van de microbiota kunnen beïnvloeden. Hierbij kunt $u$ denken aan de invloed van een typisch westerse voeding, bestaande uit een hoge inname van vet en dierlijke eiwitten en lage inname van vezels, ten opzichte van een dieet bestaande uit veelal plantaardige producten met een hoge vezelinname. Bij grote dieetveranderingen kunnen verschillen al binnen een dag gemeten worden. Daarmee kan ons dieet het microbioom beïnvloeden. Ook andere factoren kunnen het microbioom beïnvloeden waarbij $u$ kunt denken aan medicatiegebruik zoals antibiotica en zuurremmers, of bijvoorbeeld stress.

Samenvattend verstaan we onder darmgezondheid een effectieve afbraak en opname van voedingsstoffen, een goed functionerend immuunsysteem en barrièrefunctie, een normale stabiele samenstelling en activiteit van onze microbiota, samen met de afwezigheid van ziekte en een gevoel van algemeen welbevinden.

Binnen mijn leerstoel richt ik me op het begrijpen en beïnvloeden van darmgezondheid in de context van veel voorkomende darmgerelateerde aandoeningen, met een belangrijk accent op de interactie tussen voeding en darmfunctie. Verstoringen kunnen leiden tot relatief milde klachten, maar kunnen ook geassocieerd zijn met inflammatoire en maligne aandoeningen.

Voor het meten van darmgezondheid is er behoefte aan niet-invasieve markers voor vroegtijdige opsporingen van verstoorde darmfuncties, voor de prognose van ziekte en voor de evaluatie van interventies. Gezien de grote verschillen tussen individuen in microbiota 
samenstelling maar ook in voedingsinname, dienen we hierbij rekening te houden met verschillen tussen personen.

Een typisch westerse voeding, leidt niet alleen tot overgewicht, maar is ook van invloed op onze barrièrefunctie en het microbioom. Naast zijn uitspraak dat alle ziekten in de darm beginnen, had Hippocrates ook een andere beroemde uitspraak: Let Food be Thy Medicine (ofwel 'Laat voeding uw medicijn zijn'). Ook heden ten dage, gaan we ervan uit dat er nog veel winst te behalen is door verder in te zoomen op de effecten van voeding. Hierbij dienen we niet alleen oog te hebben voor de effecten van een relatief lage inname van groente, fruit en vezels, en een hoge inname van vet en dierlijke eiwitten, maar ook voor de hoge inname van verwerkte producten en kant-en-klaar maaltijden met diverse additieven. Deze additieven zijn veelal toegelaten in de voeding op basis van toxiciteit, maar de effecten op het microbioom en de darm barrière zijn nog nauwelijks onderzocht.

Voor het begrijpen van darmgezondheid is het belangrijk dat we inzicht krijgen in de interactie tussen diverse darmfuncties door samen te werken met diverse disciplines.

Daarnaast kunnen we ook stappen maken door te leren van diverse ziektes en te kijken naar dwarsverbanden. Dit doen we nog beperkt doordat we veelal met ons eigen vakgebied bezig zijn. Mijns inziens is er nog meer ruimte voor samenwerking, zowel met betrekking tot meer technische expertise alsook met betrekking tot onderliggende mechanismen van ziekte. Ik ben van mening dat we verder komen als we krachten bundelen en ook binnen de universiteit meer in teamverband werken, waarbij we gebruik maken van elkaars kracht op het gebied van onderzoek, onderwijs, management en organisatie.

Binnen mijn leerstoel richt ik me op veel voorkomende darmaandoeningen, maar is er ook samenwerking op het gebied van de lever en metabole aandoeningen. Vandaag zal ik me richten op de focus van mijn onderzoek, betreffende een meer milde aandoening, het prikkelbare darmsyndroom, en een meer ernstige ontstekingsziekte van de darm, IBD. Dit zijn beiden veel voorkomende multifactoriële 
darmaandoeningen, waarbij de intestinale microbiota, het immuunsysteem en een verstoorde barrièrefunctie een rol spelen, naast genetische en omgevingsfactoren. Ik zal beide darmziekten en de relatie met onderzoek op het gebied van darmgezondheid kort toelichten.

Het prikkelbare darm syndroom ofwel in het Engels 'Irritable Bowel syndrome', afgekort IBS, is een veel voorkomende chronische darmaandoening, die gekenmerkt wordt door buikpijn samenhangend met een veranderde stoelgang, en klachten zoals een opgeblazen gevoel en winderigheid. Het komt veel voor. Ongeveer $6 \%$ van de bevolking heeft IBS volgens de symptoom gebaseerde Rome criteria. Echter, een nog hoger percentage, zo'n 10-15\% van de bevolking, heeft regelmatig last van darmklachten. Dat betekent dat ook hier vandaag diverse gasten aanwezig zijn die regelmatig last hebben van darmklachten, daarvan hinder ondervinden en vaak zelf proberen klachten te beperken door hun voeding of leefstijl aan te passen. Bij IBS maken we onderscheid tussen mensen die met name last hebben van diarree, van constipatie of een mix daarvan.

Ondanks dat IBS vanuit biomedisch perspectief niet ernstig verloopt, heeft het wel veel impact op de kwaliteit van leven van deze patiënten en gaat het gepaard met relatief hoge kosten voor de gezondheidszorg en de maatschappij. De behandeling is een uitdaging. De meeste middelen zijn gericht op het behandelen van de klachten en hebben maar een beperkte effectiviteit. Dit hangt samen met het feit dat de oorzaak van de klachten niet geheel duidelijk is. We weten inmiddels dat veel factoren een rol kunnen spelen. Zo is er bij deze patiënten vaker sprake van een veranderde darmmotiliteit; een deel van de patiënten heeft een verhoogde viscerale gevoeligheid, een laaggradige ontsteking in de darm en/of een verstoorde barrièrefunctie. Daarnaast is er een andere microbiota samenstelling bij patiënten met IBS en is er vaker sprake van angst, depressie en stress. IBS is een typisch voorbeeld van een aandoening waar de hersen-darm as betrokken is. Dit komt ook tot uiting door een verstoorde interactie tussen de hersenen en de darmen, onder andere door veranderingen in het serotonine metabolisme. Op dit moment weten we nog niet goed welke combinatie van factoren bij 
welke patiënten tot bepaalde klachten leidt. Verder inzicht hierin is nodig om de behandeling en de kwaliteit van leven van deze patiënten te verbeteren.

Zo'n 70\% van de patiënten geeft aan dat hun klachten samenhangen met voeding; met eten in het algemeen of met specifieke voedingsproducten. Hierbij worden met name tarwe en graanproducten genoemd, maar ook gasvormende groente, zuivel, vetrijk eten en gekruid eten. Patiënten passen hun voedingsinname vaak aan, zonder begeleiding van een diëtist. We hebben gezien dat de kwaliteit van hun dieet daardoor vaak minder goed is dan die van de algemene bevolking en niet voldoet aan de Nederlandse richtlijnen gezonde voeding. We moeten leren begrijpen in welke subgroepen van de patiënten bepaalde voedingsmiddelen tot bepaalde klachten leidt en of dat samenhangt met een erfelijke aanleg of bijvoorbeeld de samenstelling van hun microbiota.

Vanwege de grote heterogeniteit in klachten en in oorzaken bij IBSpatiënten zijn we een aantal jaren geleden binnen de afdeling gestart met een groot cohort, waarbij we door een goede samenwerking tussen het lab en de MDL-artsen Daniel, Johanna en Jose onder leiding van Ad Masclee, op gestandaardiseerde wijze informatie verzamelen van IBSpatiënten, maar ook biomaterialen opslaan voor verder onderzoek. Hierin proberen we markers te vinden voor onderliggende processen die tot klachten leiden en die mogelijk kunnen voorspellen of een bepaalde behandeling succesvol zal zijn. Hiervoor hebben we ook binnen Europa de krachten gebundeld. Eerst hebben we gezamenlijk afspraken gemaakt hoe deze patiënten in kaart te brengen en welke materialen te verzamelen zodat we gegevens kunnen samenvoegen. Momenteel staan we aan de start van een groot project om met experts uit heel Europa te onderzoeken welke factoren tot klachten leiden bij bepaalde patiënten.

Inflammatoire darmziekten, ofwel IBD, zijn chronische ontstekingsziekten van de darm en omvat colitis ulcerosa en de ziekte van Crohn. Colitis ulcerosa wordt gekenmerkt door een aaneengesloten ontsteking in de dikke darm, die start vanuit de anus en zich beperkt tot 
het slijmvlies van de darmwand. De ziekte van Crohn kan verspreid voorkomen in het hele maagdarmkanaal, van de mond tot de anus, maar komt het meeste voor in de dikke darm en laatste deel van de dunne darm. De ontsteking kan alle lagen van de darmwand omvatten en kan ook leiden tot vernauwingen of fistels.

Zowel de ziekte van Crohn alsook colitis ulcerosa worden gekenmerkt door periodes van opvlammingen afgewisseld met rustige periodes. Het grillige beloop wisselt sterk tussen personen. Op dit moment weten we niet waarom de ziekte bij bepaalde mensen relatief rustig verloopt en bij andere mensen ernstig verloopt met langdurige en/of frequente opvlammingen. Zelfs als de ontsteking in de darm onder controle lijkt, is er toch vaak sprake van een verminderde kwaliteit van leven bij deze patiënten. Ze voelen zich niet goed genoeg om bijvoorbeeld naar school of naar het werk te gaan, onder andere door hun darmklachten maar ook door bijvoorbeeld klachten van vermoeidheid. We willen daarom beter begrijpen welke factoren een opvlamming uitlokken en hoe we ervoor kunnen zorgen dat het gevoel van algemeen welbevinden van deze patiënten verbetert.

Bij IBD is er sprake is van een verstoorde immuunrespons tegen de eigen microbiota, samen met een erfelijke aanleg en de rol van omgevingsfactoren. Ook is er toenemend bewijs dat de darm barrière verminderd is, met name tijdens een opvlamming. Door passage van bacteriën en toxines kan dit verder bijdragen aan de ontsteking in de darm.

Ondanks deze kennis, weten we niet hoe de opvlammingen precies ontstaan en waarom dit verschilt tussen patiënten. Hier willen we meer inzicht in krijgen, zodat we de kans op een opvlamming kunnen verminderen. Daarnaast hopen we niet-invasieve markers te vinden die deze opvlammingen zo vroeg mogelijk aan kunnen tonen om snel in te kunnen grijpen.

Net als bij IBS, werken we hier ook weer zeer nauw samen met de kliniek. Reeds in 1991, heeft mijn promotor Reinhold Stockbrügger het IBD Zuid-Limburg cohort opgezet. Hierbij zijn alle volwassen patiënten met een nieuwe diagnose IBD geregistreerd en zijn op 
gestandaardiseerde wijze klinische gegevens verzameld. Inmiddels is dit cohort voortgezet door mijn collega Marieke Pierik en mijzelf en is in 2007 ook een biobank toegevoegd aan het cohort. Op dit moment hebben we informatie van meer dan 4000 patiënten en van meer dan 1700 patiënten hebben we ook bloed, ontlasting en uitademingslucht voor verder onderzoek. De kracht van dit cohort is het populatiegebaseerde karakter, met informatie van mensen met een milde tot ernstige IBD. Hierdoor kunnen we leren van veranderingen in de tijd en van verschillen in ziektebeloop tussen de patiënten.

In de 2 linker grafieken ziet $u$ bijvoorbeeld dat het aantal nieuwe gevallen van de ziekte van Crohn en van colitis ulcerosa de laatste 10 jaar is toegenomen in Zuid-Limburg. Dit wijst op een bijdrage van omgevingsfactoren, waaronder voeding. Daarnaast zagen we dat ondanks de introductie van nieuwe geneesmiddelen en een afname van het aantal hospitalisaties en operaties, de kans op het ontwikkelen van complicaties zoals fistels en vernauwingen, nog niet is verbeterd. Dit is te zien in de rechter grafiek.

Binnen de afdeling is er een goede samenwerking met de kliniek. We maken gebruik van patiënten materiaal voor onderzoek op het lab en koppelen dat aan de klinische gegevens van de patiënt. Hierdoor kunnen we samen stappen maken in het beter begrijpen van factoren die het ziektebeloop beïnvloeden, zowel bij IBD als bij IBS.

In de ontlasting samples van onze cohorten, hebben we onder andere onderzoek gedaan naar de microbiota samenstelling en activiteit, hetgeen aantoonde dat deze anders was bij patiënten met IBD en IBS. Niet alleen de samenstelling was anders maar ook de metabole activiteit. Bij patiënten met IBD waren bijvoorbeeld minder metabole pathways aanwezig die betrokken waren bij de fermentatie van koolhydraten en productie van korteketenvetzuren, die we zien als gunstig. 
Het is interessant te zien dat deze metabole activiteit niet alleen gemeten kan worden in ontlasting, maar ook in uitademingslucht. Hier werden metabolieten gevonden die sterk correleren met de microbiota.

Ook bleken bepaalde metabolieten te correleren met darmklachten, zowel bij patiënten met IBS alsook bij mensen in de algemene bevolking. Daarnaast vonden we dat bepaalde combinaties van vluchtige stoffen gebruikt kunnen worden als een marker voor actieve ziekte bij patiënten met IBD. Dit vonden we ook voor de microbiota waarbij de combinatie van 50 verschillen bacteriën betrouwbaar actieve ziekte konden aantonen. De toegevoegde waarde van deze bevindingen in de kliniek moet nog verder onderzocht worden.

Inmiddels hebben veel onderzoeksgroepen aangetoond dat de microbiota anders is bij IBD en bij IBS. De volgende stap is echter beter te begrijpen of dat voor alle patiënten geldt, daar er aanwijzingen zijn dat dit ook binnen de ziektebeelden kan verschillen. Het lijkt zeer waarschijnlijk dat verstoringen in het microbioom een belangrijke rol speelt bij een subgroep van de patiënten, terwijl andere factoren meer op de voorgrond staan bij andere patiënten.

Hiervoor gaan we de bestaande IBD- en IBS-cohorten verder uitbouwen met oog voor verschillen tussen patiënten. Hierbij willen we patiënten over de tijd volgen door herhaaldelijk samples te verzamelen, te kijken naar de rol van en veranderingen in bijvoorbeeld voeding en psychologische factoren; en dit te koppelen met het klinisch beloop en klachten. Dit wordt mede mogelijk gemaakt door gestandaardiseerde registratie door de artsen in de kliniek en het gebruik van e-health tools. Hierin is al een hele mooie start gemaakt door de succesvolle tool 'MijnIBDcoach', ontwikkeld door mijn collega, waarmee patiënten veilig op afstand gemonitord kunnen worden, maar daarnaast ook extra informatie verzameld kan worden over omgevingsfactoren die de ziekte kunnen beïnvloeden. Hiervoor werken we nauw samen met diverse onderzoeksgroepen in Nederland om de krachten te bundelen. 
Ik ben ook zeer erkentelijk voor de goede samenwerking met diverse onderzoekers binnen de onderzoeksschool Nutrim. Deze onderzoeksschool richt zich op translationeel onderzoek naar chronische, metabole en inflammatoire aandoeningen, met specifiek aandacht voor de rol van voeding, en met het doel bij te dragen aan gezondheid middels een gepersonaliseerde benadering. Mijn leerstoel darmgezondheid sluit hier nauw bij aan.

Gecombineerde analyses van grote data sets betreffende de microbiota compositie, metabolieten, het genotype, samen met klinische en omgevingsfactoren is nodig om inzicht te krijgen in het ziekteproces en verschillen tussen patiënten. De bestaande en vruchtbare samenwerkingen met de afdelingen microbiologie, toxicologie, heelkunde en humane biologie en data science, zowel binnen onze universiteit alsook daarbuiten, zullen verder uitgebouwd worden. Daarnaast willen we onderzoeken of de veranderingen in de microbiota samenstelling of activiteit samenhangen met de respons op behandeling, maar bovenal is het belangrijk om verder inzicht te verkrijgen in wat deze veranderingen betekenen bij het ontstaan en beloop van IBD en IBS.

Ons onderzoek richt zicht hierbij met name op de effecten van de microbiota op de darm barrière en de invloed van voeding hierop. We moeten echter niet vergeten dat een andere microbiota samenstelling meer effecten kan hebben en bijvoorbeeld ook de werking van medicijnen kan beïnvloeden. Er zijn aanwijzingen dat dit ook bij IBD een rol kan spelen.

Om verder inzicht te krijgen in bacteriën en andere factoren die de darm barrière kunnen verstoren, maken we gebruik van darmmodellen. Door nauwe samenwerking met de kliniek, en uiteraard met toestemming van de patiënt, is het mogelijk stukjes darmweefsel te verkrijgen als patiënten een darmonderzoek moeten ondergaan ten behoeve van de klinische zorg.

Uit deze darmbiopten kunnen we crypten isoleren met daarin stamcellen, zoals aangegeven in figuur $A$, die we vervolgens in speciaal medium kunnen uitgroeien tot een darm organoïde ofwel een minidarm 
zoals te zien in figuur B. Vervolgens hebben we dit geoptimaliseerd tot bolvormige organoïden, zoals in figuur $C$ en $D$ te zien. In figuur $D$ zien we dat de groene kleurstof niet naar binnen lekt, hetgeen betekent dat de barrière intact is.

Deze darm organoïden kunnen we dan op het lab blootstellen aan bijvoorbeeld ontstekingsmediatoren, bacteriële producten of voedingsstoffen om te onderzoeken hoe de darm barrière beïnvloed wordt, welke mechanismen hieraan ten grondslag liggen en hoe we dit kunnen verbeteren met bepaalde voedingsstoffen of medicijnen.

Op deze dia ziet $u$ hiervan een voorbeeld. In ons organoïde model hebben we aangetoond dat stoffen in plasma van patiënten met de ziekte van Crohn ervoor zorgen dat de darm barrière lek wordt. Hierbij bleken met name ontstekingsmediatoren een belangrijke rol te spelen. Een combinatie van deze ontstekingsmediatoren ofwel cytokines leidt tot een verstoring van de darm barrière. Deze verstoring kan worden verbeterd door het geneesmiddel prednisolon. Hierbij hebben we geleerd welke processen in de epitheelcellen daarbij betrokken zijn. In de nabije toekomst, zullen we het organoïde model meer ziekte- en gastheer-specifiek maken door het te combineren met bijvoorbeeld bloed en ontlasting van een patiënt, en door co-cultuur met andere celtypen.

Op dit moment is er ook in de media veel aandacht voor de processen die plaatsvinden in de darm en het belang van de microbiota. Dit is ook te zien in de diverse boeken die de laatste jaren uitgekomen zijn en die zeer populair zijn. Het is mooi te zien dat er zoveel interesse is in onze darmgezondheid en dat veel mensen geïnteresseerd zijn te leren hoe ze hieraan bij kunnen dragen door middel van hun voeding. Ik zie het als een belangrijke rol van de wetenschap om dit te steunen maar ook om kritisch te blijven en te zorgen dat de juiste informatie bij het algemene publiek komt. Ook betere uitleg en begrip of en waarom bepaalde voedingsmiddelen tot klachten kunnen leiden is hierbij belangrijk, om te voorkomen dat mensen hun dieet gaan aanpassen met een slechte voedingskwaliteit tot gevolg. Hierdoor kunnen op korte 
termijn klachten verminderen, maar op lange termijn ook weer andere problemen ontstaan. Zowel bij IBS als bij IBD zien we dat de voedingskwaliteit vaak niet optimaal is en er vaak ook aanwijzingen zijn voor een verminderde voedingstoestand. Bij overdracht van kennis is het daarom ook belangrijk de patiënten te betrekken, te leren van hun ervaringen en met hen samen te werken aan een betere voeding, om hopelijk daardoor hun darmgezondheid en algemeen welbevinden te verbeteren.

Ook een goede samenwerking met de industrie is belangrijk. We kunnen onze darmmodellen gebruiken om bijvoorbeeld de effecten van medicijnen en stoffen in de voeding te onderzoeken. Onze goed gefenotypeerde biobanken cohorten zijn waardevol voor bijvoorbeeld de identificatie en validatie van biomarkers. Hierbij is het essentieel dat we onafhankelijk zijn in de uitvoering van het onderzoek en de interpretatie van de resultaten. Echter met goede afspraken is dit zeer wel mogelijk. Het 'Top Institute Food and Nutrition' en bijvoorbeeld het Carbohydrate Competence Center tonen de kracht van samenwerking tussen kennisinstellingen en meerdere industriële partners.

Bij overdracht van onze kennis is ook een belangrijke rol weggelegd voor het onderwijs binnen de faculteit. Het is belangrijk een toekomstige generatie op te leiden die nieuwsgierig is, die belang hecht aan kwalitatief goed onderzoek en kritisch kijkt naar de bevindingen. De master opleiding tot art en klinisch onderzoeker is hierin een heel mooi voorbeeld, waarbij we proberen toekomstige artsen op te leiden die oog hebben voor de vertaling van onderzoek naar de kliniek en terug. Het is onze taak de toekomstige generatie enthousiast te maken en hierin een goede basis te geven. Hierbij is het ook belangrijk dat we nieuwe kennis delen met de studenten.

Door gebruik te maken van goed gekarakteriseerde patiënten cohorten met biobank, in nauwe samenwerking tussen lab en kliniek, en aangevuld met interventie studies, is het doel van mijn leerstoel het begrijpen en beïnvloeden van darmgezondheid door multidisciplinair en translationeel onderzoek. Hierbij richt ik me op van veel voorkomende 
darmaandoeningen, met deels overlappende verstoringen in darmfunctie en een gradiënt van normaal-mild-ernstig. Hierbij is het doel voor de komende jaren onder andere om de bestaande cohorten uit te bouwen voor verder onderzoek naar de interactie tussen darm barrière, microbiota en voeding met aandacht voor verschillen tussen patiënten.

Daarbij gaan we verder inzetten op het begrijpen van de functionele consequenties en onderliggende processen, zodat we uiteindelijk meer inzicht krijgen in de mechanismen van ziekten en nieuwe markers kunnen identificeren voor een meer gepersonaliseerde benadering en verbetering van ziekte uitkomst en kwaliteit van leven.

Tot slot wil ik graag een aantal mensen bedanken, zonder wie ik hier vandaag niet had gestaan. De vele onderzoeken zijn uitgevoerd door een enthousiaste groep promovendi en postdocs. Ik vond het een eer en een plezier om jullie te hebben mogen begeleiden en jullie een stap verder te brengen in jullie carrière.

Ik werk met veel afdelingen en veel gewaardeerde collega's samen binnen de universiteit, waaronder de afdelingen microbiologie, toxicologie, heelkunde, en humane biologie; maar ook in Nederland en daarbuiten. Omdat ik bang ben iemand te vergeten ga ik niet iedereen met naam noemen. Bedankt voor de fijne samenwerking en hopelijk mogen er nog veel mooie projecten samen volgen.

Met enkele collega's heb ik een zeer intensieve samenwerking. Marieke Pierik, John Penders en Daniel Keszthelyi. Ik waardeer de samenwerking met jullie enorm. Doordat we complementair zijn en gebruik maken van elkaars kracht hebben we samen al veel mooi onderzoek mogen doen. Ik kijk uit naar de toekomst.

Mijn promotor Reinhold Stockbrugger heeft mede gezorgd voor de basis van mijn carrière. Ik ben dan ook zeer erkentelijk voor de alle mogelijkheden die hij me heeft gegeven om mezelf te ontwikkelen. Ik vind het erg jammer dat hij niet meer onder ons is en deze dag niet mee kan maken. Hierbij wil ik ook mijn mede-co-promotoren Ellen Stobberingh en Adriaan de Bruine betrekken en mijn leidinggevende Ad Masclee. Beste $\mathrm{Ad}$, onder jou heb ik me verder mogen ontwikkelen 
waarbij je me alle vrijheid hebt gegeven en altijd je vertrouwen uitsprak in mijn functioneren. Heel veel dank voor je steun. Ook een speciaal woord van dank voor de fijne samenwerking met Nutrim, Annemie, Pascal en Fred; en aan mijn klasje voor de broodnodige reflectie.

Tot slot vrienden en familie die er altijd zijn en zorgen voor de nodige ontspanning.

Pap en mam, jullie hebben me altijd gesteund en gestimuleerd om op eigen benen te staan en jullie hebben met besmet met het fiets-virus. Ik heb heel dankbaar voor alles en ook dat jullie er vandaag bij kunnen zijn en nog steeds kunnen genieten van jullie vakantieadres in Maastricht. Lieve Karel, zonder jouw steun en vertrouwen was dit niet gelukt. Nog een deadline volgende week en dan komt er hopelijk weer een wat rustigere tijd.

Ik heb gezegd. 